\title{
Relationship Between the Application of Foliar Chemicals to Reduce Common Scab Disease of Potato and Correlation with Thaxtomin A Toxicity
}

Robert S. Tegg, Ross Corkrey, and Calum R. Wilson, Tasmanian Institute of Agricultural Research, University of Tasmania, New Town Research Laboratories, 13 St. Johns Avenue, New Town, Tasmania 7008, Australia

\begin{abstract}
Tegg, R. S., Corkrey, R., and Wilson, C. R. 2012. Relationship between the application of foliar chemicals to reduce common scab disease of potato and correlation with thaxtomin A toxicity. Plant Dis. 96:97-103.

Production of the phytotoxin thaxtomin A by pathogenic Streptomyces spp. is essential for induction of common scab disease in potato. The disease can be significantly reduced by a range of chemicals applied as foliar sprays before tuber initiation. We tested a range of chemicals that had previously demonstrated varying capacities to reduce common scab for both disease suppression and their ability to inhibit thaxtomin A toxicity in both 'Desiree' and 'Russet Burbank' potato. Our results for disease suppression generally supported previous studies. Our tuber slice assays with thaxtomin A showed a strong correlation between the ability of the chemical to suppress common scab symptom develop-

ment and the ability of the chemical to inhibit thaxtomin A toxicity. A Bayesian measurement error linear regression model was derived for each cultivar and trial and demonstrated a clear positive relationship between disease and thaxtomin-A-induced necrosis. The relationships obtained were much stronger than would have been obtained without adjustment for measurement error. This demonstrates that disease mitigation using chemical foliar sprays is strongly correlated with the ability of the chemical to inhibit thaxtomin A toxicity, suggesting this mechanism as a key mode of action for understanding this novel disease control strategy.
\end{abstract}

Common scab caused by infection with pathogenic Streptomyces spp. is one of the most important diseases of the potato (Solanum tuberosum L.) worldwide (19). Annual losses in Tasmania, Australia alone are estimated at approximately $4 \%$ of the industry value (34). All pathogenic Streptomyces spp. produce the phytotoxin thaxtomin A, whereas nonpathogenic strains do not $(2,16)$, demonstrating its essential role in disease induction $(11,14)$.

There is no single effective management option for this disease; rather, an integrated approach is required. Foliar sprays provide a novel strategy that has previously been shown to be highly effective in suppressing this recalcitrant soilborne disease $(20,22,23,30)$ but other undesirable side effects (tuber distortion and yield reduction) have led to limited uptake of this technology $(20,23)$. Our research group has studied the mechanisms by which 2,4-dichlorophenoxyacetic acid $(2,4-\mathrm{D})$ may reduce this disease. We found that foliar-applied 2,4-D (and auxin analogues) migrated to the tuber tissue and inhibited thaxtomin A induced necrosis. Our studies and others also confirmed that 2,4-D, at efficacious concentrations does not affect Streptomyces scabiei growth $(23,30)$ or thaxtomin A production in vitro (30), confirming that the novel disease control is through inhibition of thaxtomin A by the applied chemical. Also, 2,4-D as a powerful synthetic auxin has an impact on potato tuber anatomy and physiology; however, it is not conclusively known whether these changes have any role in affecting common scab disease development (30). Whereas 2,4-D is primarily known as a herbicide, it is also used commercially in potato production at low concentrations to enhance red skin coloration, without apparent tuber distortion or yield effect (32).

McIntosh and others $(20,22,23)$ tested over 100 compounds for disease control and found chemicals that either decreased, increased, or had no effect on common scab disease development. Many showed potential, some without negative side effects on tuber quality and yield, but the research was not carried forward to

Corresponding author: R. S. Tegg, E-mail: Robert.Tegg@utas.edu.au

Accepted for publication 18 August 2011.

http://dx.doi.org/10.1094/PDIS-05-11-0397

(C) 2012 The American Phytopathological Society commercial adoption; this may be partly attributable to the usage of irrigation management as a viable alternative control for common scab in the United Kingdom. However, in Australia and other production regions of the world, where water is a scarce resource and irrigation management has provided relatively poor disease control, improved disease management with a simple and cheap foliar spray would be highly sought after by industry (30).

A relationship between necrosis and disease has been established for 2,4-D such that the amount of reduction in thaxtomin-A-induced necrosis measured in vitro (in tuber slice assays) corresponds with the amount of reduction of disease observed in the tubers (30). However, it has not been demonstrated whether other chemicals that have the capacity to inhibit or promote common scab have an effect on thaxtomin-A-induced toxicity. If a relationship was established, this would provide insight into a broader mechanism for chemically induced resistance to common scab. In this study, we chose to utilize a Bayesian measurement-error modeling approach to enable relationships to be modeled linking thaxtomin A toxicity and disease response.

A measurement-error model allows for adjustment due to errors in both explanatory and response variables, unlike a conventional regression model that assumes the explanatory variables are precisely known. The use of Bayesian methods allows complex models to be constructed with greater ease than with classical approaches (3). Unlike classical methods, Bayesian statistics involve the use of prior distributions (9), usually in the form of probability distributions. The results of a Bayesian analysis provide a direct description of the probabilities of the magnitude of parameters of interest.

Bayesian models may enable the identification of one parameter to aid in the prediction of another related parameter. Thaxtomin A resistance is a key mechanism postulated for resistance to common scab $(1,12,13,34,35)$ and its toxicity can be easily measured in a quick and rapid tuber slice assay (31). Its measurement and modeling in response to various chemical treatments may enable the efficaciousness of those treatments to be accurately assessed, without the need for expensive and time-consuming disease trials. In the case of common scab, sporadic disease intensities resulting from varied environmental influences can make assessing the effectiveness of given controls unpredictable $(12,29)$. An initial assay could negate the need for assessment of disease (12) for assessing 
the likely suitability of a given control. This may improve the ability to identify and rapidly screen a range of different chemical treatments.

The aim of this study was to assess a selection of compounds applied as a foliar spray to young potato plants for their relative ability to reduce common scab and to determine the association of this with their relative ability to inhibit thaxtomin A toxicity.

\section{Materials and Methods}

Pathogen culture and plant establishment. Pathogenic $S$. scabiei strains \#20 or G\#32 were initially isolated in 1990 from common scab diseased potato tubers from Tasmania and Victoria, Australia, respectively. Both S. scabiei isolates are highly pathogenic, producing high levels of thaxtomin A (R. King, AgriFood Canada, personal communication) and contain the necl gene (unpublished data). Inoculum was prepared by suspending spores harvested from a 2-week-old culture grown on ISP2 medium (27) in $5 \mathrm{ml}$ of sterile water, and adding this to a sterilized mixture of $100 \mathrm{~g}$ of vermiculite and $500 \mathrm{ml}$ of SAY solution (sucrose at 20 $\mathrm{g} /$ liter, $L$-asparagine at $1.2 \mathrm{~g} / \mathrm{liter}, \mathrm{K}_{2} \mathrm{HPO}_{4}$ at $0.6 \mathrm{~g} / \mathrm{liter}$, and yeast extract at $10 \mathrm{~g} /$ liter; $\mathrm{pH}$ 7.2). Inoculum was incubated at $24^{\circ} \mathrm{C}$ in the dark for 14 days, whereupon profuse sporulation was observed.

Plastic pots $(20 \mathrm{~cm}$ in diameter, $20 \mathrm{~cm}$ in height, 4.7 -liter capacity) were filled with a potting mix containing sand, peat, and composted pine bark (10:10:80; $\mathrm{pH}$ 6.0) premixed with Osmocote 163.5-10 NPK resin-coated fertilizer (Scotts Australia Pty Ltd. Baulkham Hills, Australia) at the rate of $6 \mathrm{~kg} / \mathrm{m}^{3}$. In trials where pathogen amendments were included, inoculum (approximately $20 \mathrm{~g}$ ) was mixed to the depth of the pot (inoculum concentration not determined). Potato plants S. tuberosum 'Russet Burbank' (moderately resistant to common scab) and 'Desiree' (susceptible to common scab) (31) were provided as visually disease-free certified seed (Department of Primary Industries, Devonport, Tasmania), with tubers planted into individual pots. Pots were placed outside on benches (replicates) exposed to the ambient environment in Hobart, Tasmania. Approximately $5 \mathrm{ml}$ of water was applied to each pot every third day. This regime allowed the potting mix to dry substantially between waterings. Additional plants were grown alongside the trial to allow periodic monitoring for onset of tuber initiation without disturbing the trial plants. No pesticides were applied during the trial period. A soluble fertilizer was applied monthly (Miracle-Gro Water-Soluble all-purpose plant food, 1513.1-12.4 NPK; Scotts Australia Pty Ltd.).

Spray treatments. All spray treatments were timed to coincide with the critical infection period, which occurs 2 to 6 weeks after tuber initiation (ati) $(17,18)$, determined by observations of additional (non-trial) plants. All treatments were applied as sequential triple sprays applied at 10, 20, and 30 days ati. Spray treatments were applied as a fine mist to leaves until run-off. Absorbent cotton towels were placed on the soil surface during spraying, to ensure that soil was protected from direct spray contact, and towels were removed immediately after treatment.

Spray treatments included water controls and nine other compounds (Table 1). These compounds and concentrations utilized were based on prior published results $(20,21,23,30)$, and were a representation of chemicals that had either increased, reduced, or had no affect on common scab disease (Table 1). All chemicals were sourced from Sigma-Aldrich (St. Louis) except for 2,4-D (am) (i.e., Amicide625) obtained from Nufarm Pty Ltd. (Victoria, Australia), 3,6-DCP from AK Scientific (California), and 2,5-D and 3,5-D, which were obtained by direct synthesis, through the condensation of their dichlorophenol form with monochloroacetic acid (25). All spray treatments, including controls, contained $0.2 \%$ ethanol (for dissolution of the chemicals) and Tween 20 at 0.2 g/liter (wetting agent).

Pot trial design and treatments. The effects of novel foliar sprays on scab development and subsequent tuber sensitivity to thaxtomin A were studied in three pot trials in 2009 and 2010. In all three trials, the same nine chemicals were tested (Table 1) on both Desiree and Russet Burbank. In pot trials 1 and 2, S. scabiei isolate \#20 was used, and trial 3 used $S$. scabiei isolate G\#32. In all trials, treatments were replicated $(n=5$ : trial $1 ; n=3$ : trials 2 and 3 ) and pots arranged in a randomized block design. The first foliar sprays were applied on 13 February 2009 (trial 1), 1 March 2010 (trial 2), and 15 March 2010 (trial 3), with all tubers harvested at senescence 10 weeks later (equivalent to 16 weeks after planting) and scored for disease and tuber yield.

Disease and tuber yield assessment. After plants had fully senesced, tubers were harvested, rinsed gently under cold running water, and air dried. Tubers were assessed immediately, with the number and individual weight of each tuber per pot recorded. Tubers weighing more than $4.0 \mathrm{~g}$ were assessed for disease. Both disease incidence (percentage of tubers with disease lesions) and severity (the mean surface area covered by lesions and the deepest lesion per tuber) assessments were done using methods described previously $(15,31,33)$. Both disease incidence and the mean surface area covered by lesions are important measures used for certification in Australia and the United Kingdom, respectively. The other severity measurement (deepest lesion per tuber) is extremely important within the Australian processing sector, with deep-lesioned tubers resulting in rejection of crops at processing factories (P. Hardman, Simplot Australia, personal communication). After assessment, tubers were placed into storage at $4^{\circ} \mathrm{C}$ for 2 weeks, prior to undertaking the tuber slice assay.

Sensitivity of tubers to thaxtomin A using a tuber slice assay. Tubers from each chemical spray treatment and cultivar were tested for thaxtomin A tolerance using a tuber slice bioassay refined by Tegg and co-workers (28). The tuber slice assay is the most suitable method for accurately quantifying tuber tissue response to thaxtomin A, providing a more consistent response than other tissue types (e.g., leaf tissue or outer tuber periderm; 29).

Table 1. Chemicals tested and rates used in this study as foliar sprays for common scab control and thaxtomin A toxicity suppression ${ }^{\mathrm{x}}$

\begin{tabular}{|c|c|c|c|c|c|}
\hline \multirow[b]{2}{*}{ Active constituent } & \multirow[b]{2}{*}{ Abbrev. } & \multirow[b]{2}{*}{ Conc. $^{y}$} & \multicolumn{3}{|c|}{$\begin{array}{c}\text { Previous reported performance of selected chemicals } \\
\text { against common scab }\end{array}$} \\
\hline & & & Reduction $(\%)^{\mathrm{z}}$ & Side effects & Ref \\
\hline 4-Chloro-phenoxyacetic acid & 4-CPA & $0.9 \mathrm{mM}$ & 4 & & 21 \\
\hline 2,4-Dichloro-phenoxyacetic acid & 2,4-D & $0.9 \mathrm{mM}$ & $45-92$ & Yield reduction, tuber and foliage distortion & 21,30 \\
\hline 2,4-Dichloro-phenoxyacetic acid (amide form) & 2,4-D (am) & $0.9 \mathrm{mM}$ & Not tested & $\ldots$ & $\ldots$ \\
\hline 2,5-Dichloro-phenoxyacetic acid & $2,5-\mathrm{D}$ & $0.9 \mathrm{mM}$ & Increase & $\ldots$ & 21 \\
\hline 3,5-Dichloro-phenoxyacetic acid & $3,5-\mathrm{D}$ & $0.9 \mathrm{mM}$ & 87 & Yield reduction, tuber distortion & 21 \\
\hline 5-Chloro-2-nitrobenzoic acid & CNB & $1.6 \mathrm{mM}$ & $7-73$ & & 20,30 \\
\hline 2,5-Dibromobenzoic acid & 2,5-DBB & $1.6 \mathrm{mM}$ & 71 & Slight foliage distortion & 20 \\
\hline 2,5-Dihydroxybenzoic acid & 2,5-DHB & $1.6 \mathrm{mM}$ & Increase & $\ldots$ & 20 \\
\hline 3,6-Dichloropicolinic acid & 3,6-DCP & $50 \mu \mathrm{M}$ & 73 & Slight foliage distortion & 20 \\
\hline
\end{tabular}

${ }^{\mathrm{x}}$ The previous reported performance of these selected chemicals is also provided with data on percent scab reduction, phytotoxic side effects, and relevant references (Ref).

y Concentration (active ingredient).

${ }^{\mathrm{z}}$ Variation in disease (scab) reduction is both a function of different environmental conditions and disease pressures in different experiments. 
Production and purification of the toxin thaxtomin A was as previously described (34). A selection of representative visually diseasefree whole tubers were surface sterilized with $0.5 \%$ sodium hypochlorite for $10 \mathrm{~min}$ and air dried before being cut into $0.5-\mathrm{cm}$ thick slices and placed in $90-\mathrm{mm}$ petri dishes with moist sterile filter paper (Whatman number 1). There was a total of three petri dishes (replicates) per treatment. In each replicate, three tuber slices from one single tuber were used for each tested treatment. Filter paper disks of $6 \mathrm{~mm}$ in diameter (Whatman number 1) were immersed in thaxtomin A solution (14 $\mu \mathrm{M}$ for Desiree and $7 \mu \mathrm{M}$ for Russet Burbank, all dissolved in approximately $1 \%$ acetone) for $1 \mathrm{~h}$, air dried, and placed on the potato slices (two to three disks per slice), with disks immersed in approximately $1 \%$ acetone solution and air dried used as controls. In each replicate (petri dish), each treatment had a total of seven individually-scored disks. After placement on the potato slices, $10 \mu \mathrm{l}$ of sterile distilled water was applied to each disk (1) to ensure stable contact between tuber and disk. Plates were incubated at $24^{\circ} \mathrm{C}$ in the dark and evaluated after 7 days for necrosis in the defined area under the filter paper disk: 0 $=$ no necrosis, $0.5=$ very sparse flecks, $1=$ few light-brown flecks, 1.5 = few dark-brown flecks, 2 = light-brown flecks in circle, $2.5=$ dark-brown flecks in circle, $3=$ light-brown necrosis, $3.5=$ darkbrown necrosis, and $4=$ black necrosis.

Data analysis. Data were subjected to analysis of variance using Genstat 9 (Rothamsted Experimental Station, Harpenden, Hertfordshire, UK). Data using scale ratings were derived from an interval-based scale, with a continuous, ordinal, ascending nature. Significance was calculated at $P=0.05$ as noted, and least significant difference was used for comparison of treatment means. All data were tested for normality and homogeneity of variance and no transformation was necessary.

To investigate the relationship of disease with thaxtomin A sensitivity (necrosis), a Bayesian measurement-error model was developed. Standard regression models assume that the explanatory variables are precisely known with zero error. In practice, this assumption is sometimes not the case and was known to be untrue with these data. Not allowing for such uncertainty can lead to inconsistent estimates. We assumed that the sizes of the errors do not depend on the magnitude of the measurements but it should be noted that, in general, errors can behave otherwise. We assume that the explanatory variable, necrosis, is observed with an additive error, also called a classical error model (6). While other approaches have been used $(5,28)$, by adopting a Bayesian approach we aim to avoid the computational and statistical difficulties associated with such models (8).

The model consists of a simple linear regression of the disease rating (tuber surface cover score) with necrosis as the explanatory variable. Tuber surface cover score provides the best interpretation of average disease across a pot $(30,31)$ and was the parameter modeled instead of lesion depth or percentage of tubers infected. We initially assume that the relationship may differ for each chemical requiring individual intercepts and slopes. Below we use the subscripts $i$ to refer to individual observation and $t$ to refer to chemicals 1 through 10 . The observed disease rating is assumed to be normally distributed with mean $\mu_{\mathrm{i}}$ and precision $\tau$ (reciprocal variance). The mean is defined as shown in equation a, in which $\alpha_{\mathrm{t}}$ is the intercept, $\beta_{\mathrm{t}}$ is the slope, and $v_{\mathrm{i}}$ is the unobserved true value for necrosis.

$\mu_{\mathrm{i}}=\alpha_{\mathrm{t}}+\beta_{\mathrm{t}} v_{\mathrm{i}}$

Because this is a measurement error model, we let the observed necrosis be given by a normal distribution, with mean given by the unobserved true value for necrosis, as shown in equation $b$. We estimated the value of the precision $\sigma_{\mathrm{i}}$ from the standard deviation of the necrosis ratings of the seven individually scored disks.

$N_{\mathrm{i}} \sim N\left(v_{\mathrm{i}}, \sigma_{\mathrm{i}}\right)$

Last, we assumed that the intercepts, slopes, and unobserved necrosis parameters are normally distributed with a common means: $\alpha_{\mathrm{t}} \sim N\left(\alpha_{0}, \lambda\right), \beta_{\mathrm{t}} \sim N\left(\beta_{0}, \rho\right)$, and $v_{\mathrm{i}} \sim N\left(v_{0}, \varphi\right)$. Normal distributions for explanatory and dependent variables are acceptable here because the range of data was relatively small compared with their possible range.

Having defined the model, we further defined three simpler models in which the chemicals share a common slope, a common intercept, or both. The six analyses (three trials by two cultivars) were analyzed separately and, for each, we chose one of the four possible models that obtained the minimum overall deviance.

The $\alpha_{0}, \beta_{0}$, and $v_{0}$ are assigned normal distributions with zero means and precisions of 0.001 . The precisions, $\lambda, \rho, \varphi$, and $\tau$ are all assigned vague gamma distributions with parameters 0.001 and 0.001 . When fitting the model, we zero-centered the $v_{\mathrm{i}}$ to improve model convergence.

Sensitivity studies and standard diagnostic techniques were used (4) to assess model validity. We fitted the model using Markov chain Monte Carlo methods (10) by means of JAGS software (24). The model was run for 10,000 iterations and a $10 \%$ burn-in was used.

\section{Results}

Disease performance. Across three pot trials, there were variable levels of disease incidence and severity (surface coverage and lesion depth; Table 2). Pathogenic isolate S. scabiei G\#32 (trial 3) produced significantly higher disease than S. scabiei \#20 (trials 1 and 2) and this is best demonstrated by comparing control tubers from each trial. In trial 3, Desiree had an infection percentage of $100 \%$, common scab surface coverage of $18.8 \%$, and an average lesion depth score of 2.5 whereas, in trials 1 and 2 , the highest levels recorded for each parameter were $47.2 \%, 1.9 \%$, and 2.0, respectively (Table 2 ).

The response to the application of a range of different chemicals showed similar trends (in terms of disease) across all three trials and across both Desiree and Russet Burbank. The treatments 2,5$\mathrm{D}, \mathrm{CNB}, 3,6-\mathrm{DCP}$, and 2,5-DHB consistently produced disease (tuber surface cover) comparable with the water-treated control (Table 2). One chemical, 4-CPA, produced disease comparable with the control in five analyses; however, in trial 3 with Desiree, it produced significantly $(P<0.05)$ less disease.

Other treatments $(2,4-\mathrm{D}, 2,4-\mathrm{D}(\mathrm{am})$, and 2,5-DBB) showed a consistent and significant $(P<0.05)$ ability to reduce disease (tuber surface cover) across both cultivars when compared with the watertreated control (Fig. 1). One additional treatment, 3,5-D, significantly suppressed disease compared with the water control in five analyses; however, in trial 1 with Russet Burbank, disease suppression was not significant (Table 2).

Other measures of disease were less affected by the chemical treatment applied. The mean percentage of tubers infected showed trends similar to the tuber surface cover responses although, in trial 1 and 2 , these effects were not statistically significant $(P>0.05)$. This may be partly attributable to the low disease pressure recorded in both these trials, where S. scabiei \#20 was used (infection percentages below 50\%). Where disease pressure was higher in trial 3 (S. scabiei G\#32) and infection percentages reached $100 \%$, significant treatment differences were identified and, in both cultivars, the four treatments $(2,4-\mathrm{D}, 2,4-\mathrm{D}$ (am), 3,5$\mathrm{D}$, and 2,5-DBB) produced significantly lower percentages $(P<$ 0.05 ) of infected tubers than the water-treated control (Table 2).

The impact of chemical treatment on mean greatest lesion depth was variable (Table 2). In trial 1, Desiree recorded moderate lesion depth (ratings of approximately 2.0) and treatment effects were observed with 2,4-D, 2,4-D (am), 3,5-D, and 2,5-DBB having less $(P<0.05)$ mean lesion depth than the controls. In Russet Burbank, generally superficial lesions were recorded (ratings up to 1.40) but significant differences obtained; in addition to the chemicals that suppressed lesion depth in Desiree, 2,5-D, CNB, and 3,6-DCP also recorded significantly $(P<0.05)$ lower lesion depth ratings than the control. In trial 2 , where generally only superficial lesions were recorded (ratings $<1.4$ ), there were no significant chemical treatment effects observed across both cultivars. Trial 3 recorded deeper lesion depths and, in both cultivars, significant treatment effects 
were identified; the chemical treatments: 2,4-D, 2,4-D (am), 3,5-D, and 2,5-DBB produced significantly shallower lesions $(P<0.05)$ than the control tubers.

Tuber distortion (mainly tuber elongation) was visually observed in foliar spray treatments that included dichlorophenoxyacetic acids (i.e., 2,4-D, 2,4-D (am), 2,5-D ,and 3,5-D). This distortion was observed in both cultivars tested and across all three trials.

Sensitivity of tubers to thaxtomin A using a tuber slice assay. Across all three pot trials and both cultivars (six separate analyses), significant decreases $(P<0.05)$ in thaxtomin-A-induced necrosis scores were recorded for tubers harvested from plants treated with triple foliar sprays of 2,4-D, 2,4-D (am), and 2,5-DBB compared with tubers from water control plants (Table 2; Fig. 2). One chemical, 3,5-D, suppressed thaxtomin toxicity in all six trial-cultivar combinations, though suppression was significant in only five of the six analyses.

The other chemicals generally had no significant impact on thaxtomin-A-induced necrosis. Indeed, tubers treated with foliar sprays of 2,5-D, 4-CPA, CNB, and 2,5-DHB showed an analogous response to control (water-treated) tubers (Table 2) in all six analyses (three trials across two cultivars). One chemical, 3,6-DCP, produced comparable toxin necrosis responses to the control in five analyses; however, in trial 1 with Russet Burbank, it produced significantly $(P<0.05)$ less necrosis.

Relationship of common scab disease with thaxtomin A sensitivity (necrosis). For the case of Russet Burbank in trial 1, the preferred model, with the minimal deviance, was one in which there were different slopes and intercepts for the chemicals. For all other cases, the simplest model was preferred, in which all chemicals shared the same intercept and slope. The coefficients and their 95\% credible intervals are shown in Table 3 . The observed data and mean posterior predicted fits are shown in Figures 3 and 4. For Russet Burbank in trial 1, there was an increasing positive slope showing that, as necrosis increases, so too does disease (Fig. 3). It is of interest that two distinct groups of linear regressions were observed. The first group (control, 2,5-DHB, 2,5-D, CNB, 4-CPA,

Table 2. Impact of various foliar spray treatments on common scab disease of potato 'Desiree' (Des) and 'Russet Burbank'(RB) inoculated with Streptomyces scabiei strain \#20 (trials 1 and 2) and strain G\#32 (trial 3) $)^{\mathrm{y}}$

\begin{tabular}{|c|c|c|c|c|c|c|c|c|c|c|}
\hline \multirow[b]{4}{*}{ Trial, treatment ${ }^{\mathrm{z}}$} & \multicolumn{8}{|c|}{ Common scab disease rating } & \multirow{2}{*}{\multicolumn{2}{|c|}{ Thaxtomin A sensitivity }} \\
\hline & \multicolumn{4}{|c|}{ Tuber surface cover } & & & & & & \\
\hline & \multicolumn{2}{|c|}{ Score $(0-6)$} & \multicolumn{2}{|c|}{ Percent } & \multicolumn{2}{|c|}{ Lesion depth score (1-4) } & \multicolumn{2}{|c|}{ Infected tubers $(\%)$} & \multicolumn{2}{|c|}{ Mean necrosis rating $(0-4)$} \\
\hline & Des & RB & Des & RB & Des & RB & Des & RB & Des & RB \\
\hline \multicolumn{11}{|c|}{1} \\
\hline Control & $0.61 \mathrm{a}$ & $0.26 \mathrm{a}$ & 1.89 & 0.58 & $2.05 \mathrm{a}$ & $1.35 \mathrm{a}$ & 47.2 & 23.4 & $2.84 \mathrm{a}$ & $2.79 \mathrm{a}$ \\
\hline 2,4-D & $0.13 \mathrm{~b}$ & $0.00 \mathrm{bc}$ & 0.40 & 0.00 & $1.40 \mathrm{bc}$ & $\ldots$ & 25.2 & 0.0 & $2.48 \mathrm{de}$ & $2.16 \mathrm{de}$ \\
\hline $2,4-\mathrm{D}(\mathrm{am})$ & $0.13 \mathrm{~b}$ & $0.03 \mathrm{bc}$ & 0.40 & 0.10 & $1.35 \mathrm{bc}$ & $1.00 \mathrm{~b}$ & 23.6 & 6.0 & $2.56 \mathrm{de}$ & $1.98 \mathrm{e}$ \\
\hline $2,5-\mathrm{D}$ & $0.62 \mathrm{a}$ & $0.27 \mathrm{a}$ & 2.04 & 0.49 & $1.78 \mathrm{ab}$ & $1.00 \mathrm{~b}$ & 43.4 & 20.0 & $2.80 \mathrm{abc}$ & $2.70 \mathrm{ab}$ \\
\hline $3,5-\mathrm{D}$ & $0.20 \mathrm{~b}$ & $0.10 a b c$ & 0.37 & 0.15 & $1.00 \mathrm{c}$ & $1.00 \mathrm{~b}$ & 18.7 & 12.5 & $2.58 \mathrm{cde}$ & $2.39 \mathrm{~cd}$ \\
\hline 4-CPA & $0.57 \mathrm{a}$ & $0.21 \mathrm{ab}$ & 1.92 & 0.63 & $2.10 \mathrm{a}$ & $1.35 \mathrm{a}$ & 42.5 & 25.5 & $2.85 \mathrm{a}$ & $2.68 \mathrm{abc}$ \\
\hline CNB & $0.40 \mathrm{ab}$ & $0.18 \mathrm{abc}$ & 1.20 & 0.39 & $1.90 \mathrm{a}$ & $1.00 \mathrm{~b}$ & 35.0 & 12.2 & 2.60 bcde & $2.65 a b c$ \\
\hline 2,5-DBB & $0.19 \mathrm{~b}$ & $0.03 \mathrm{bc}$ & 0.49 & 0.03 & $1.25 \mathrm{c}$ & $1.00 \mathrm{~b}$ & 24.3 & 5.0 & $2.40 \mathrm{e}$ & $1.64 \mathrm{f}$ \\
\hline 2,5-DHB & $0.60 \mathrm{a}$ & $0.30 \mathrm{a}$ & 1.72 & 0.63 & $2.00 \mathrm{a}$ & $1.40 \mathrm{a}$ & 40.0 & 28.0 & $2.69 \mathrm{abcd}$ & $2.69 \mathrm{ab}$ \\
\hline 3,6-DCP & $0.61 \mathrm{a}$ & $0.18 a b c$ & 1.70 & 0.28 & $1.92 \mathrm{a}$ & $1.00 \mathrm{~b}$ & 41.0 & 12.0 & $2.81 \mathrm{ab}$ & $2.42 \mathrm{bcd}$ \\
\hline$P$ & 0.002 & 0.015 & $\ldots$ & $\ldots$ & 0.02 & 0.031 & 0.254 & 0.094 & 0.001 & $<0.001$ \\
\hline $\operatorname{LSD}(0.05)$ & 0.32 & 0.20 & $\ldots$ & $\ldots$ & 0.45 & 0.25 & ns & ns & 0.220 & 0.288 \\
\hline \multicolumn{11}{|l|}{2} \\
\hline Control & $0.38 \mathrm{a}$ & $0.37 \mathrm{a}$ & 1.02 & 0.90 & 1.11 & 1.00 & 43.7 & 38.1 & $2.75 \mathrm{a}$ & $2.67 \mathrm{a}$ \\
\hline 2,4-D & $0.15 \mathrm{~cd}$ & $0.12 \mathrm{~d}$ & 0.20 & 0.15 & 1.00 & 1.00 & 28.1 & 23.7 & $2.32 \mathrm{bc}$ & $1.95 \mathrm{c}$ \\
\hline $2,4-\mathrm{D}(\mathrm{am})$ & $0.13 \mathrm{~d}$ & $0.14 \mathrm{~cd}$ & 0.20 & 0.14 & 1.00 & 1.00 & 33.2 & 28.9 & $2.35 \mathrm{bc}$ & $2.10 \mathrm{bc}$ \\
\hline $2,5-\mathrm{D}$ & $0.44 \mathrm{a}$ & $0.30 a b c$ & 1.42 & 0.60 & 1.28 & 1.00 & 46.7 & 40.3 & $2.80 \mathrm{a}$ & $2.81 \mathrm{a}$ \\
\hline $3,5-\mathrm{D}$ & $0.21 \mathrm{bcd}$ & $0.17 \mathrm{bcd}$ & 0.46 & 0.27 & 1.00 & 1.00 & 26.3 & 29.3 & $2.40 \mathrm{~b}$ & $2.34 \mathrm{~b}$ \\
\hline 4-CPA & $0.32 \mathrm{ab}$ & $0.34 \mathrm{a}$ & 0.75 & 0.90 & 1.31 & 1.08 & 47.2 & 39.8 & $2.82 \mathrm{a}$ & $2.66 \mathrm{a}$ \\
\hline $\mathrm{CNB}$ & $0.30 \mathrm{abc}$ & $0.31 \mathrm{ab}$ & 0.70 & 0.69 & 1.22 & 1.00 & 37.0 & 42.5 & $2.66 \mathrm{a}$ & $2.64 \mathrm{a}$ \\
\hline $2,5-\mathrm{DBB}$ & $0.10 \mathrm{~d}$ & $0.17 \mathrm{bcd}$ & 0.10 & 0.25 & 1.00 & 1.00 & 23.1 & 23.7 & $2.10 \mathrm{c}$ & $2.03 \mathrm{c}$ \\
\hline 2,5-DHB & $0.34 \mathrm{ab}$ & $0.31 \mathrm{ab}$ & 0.90 & 0.55 & 1.39 & 1.00 & 37.1 & 37.9 & $2.68 \mathrm{a}$ & $2.72 \mathrm{a}$ \\
\hline 3,6-DCP & $0.42 \mathrm{a}$ & $0.31 \mathrm{ab}$ & 1.21 & 0.60 & 1.22 & 1.00 & 47.1 & 39.6 & $2.76 \mathrm{a}$ & $2.63 \mathrm{a}$ \\
\hline$P$ & 0.01 & 0.015 & $\ldots$ & $\ldots$ & 0.162 & 0.474 & 0.311 & 0.342 & $<0.001$ & 0.003 \\
\hline LSD (0.05) & 0.165 & 0.162 & $\ldots$ & $\cdots$ & ns & ns & $\mathrm{ns}$ & $\mathrm{ns}$ & 0.255 & 0.265 \\
\hline \multicolumn{11}{|l|}{3} \\
\hline Control & $2.66 \mathrm{a}$ & $2.28 \mathrm{ab}$ & 18.77 & 13.13 & $2.60 \mathrm{ab}$ & $1.97 \mathrm{ab}$ & $100.0 \mathrm{a}$ & $100.0 \mathrm{a}$ & $2.62 \mathrm{a}$ & $2.71 \mathrm{ab}$ \\
\hline 2,4-D & $1.33 \mathrm{cde}$ & $0.34 \mathrm{c}$ & 4.94 & 1.35 & $1.78 \mathrm{bc}$ & $1.11 \mathrm{c}$ & $71.1 \mathrm{bcd}$ & $33.7 \mathrm{~d}$ & $2.14 \mathrm{~cd}$ & $2.11 \mathrm{~d}$ \\
\hline 2,4-D (am) & $0.99 \mathrm{e}$ & $0.76 \mathrm{c}$ & 4.11 & 2.31 & $1.86 \mathrm{bc}$ & $1.36 \mathrm{bc}$ & $70.8 \mathrm{bcd}$ & $52.8 \mathrm{c}$ & $2.16 \mathrm{bcd}$ & $2.05 \mathrm{~d}$ \\
\hline $2,5-\mathrm{D}$ & $2.14 \mathrm{abc}$ & $1.77 \mathrm{ab}$ & 14.09 & 8.85 & $2.61 \mathrm{ab}$ & $1.75 \mathrm{abc}$ & $89.2 \mathrm{ab}$ & $89.7 \mathrm{ab}$ & $2.55 \mathrm{a}$ & $2.71 \mathrm{ab}$ \\
\hline $3,5-\mathrm{D}$ & $1.23 \mathrm{de}$ & $0.33 \mathrm{c}$ & 4.00 & 0.97 & $1.00 \mathrm{c}$ & $1.22 \mathrm{c}$ & $45.4 \mathrm{~d}$ & $35.2 \mathrm{~d}$ & $2.35 a b c$ & $2.33 \mathrm{~cd}$ \\
\hline 4-CPA & $1.73 \mathrm{bcde}$ & $1.63 \mathrm{~b}$ & 9.89 & 6.95 & $2.35 \mathrm{ab}$ & $1.51 \mathrm{abc}$ & $82.2 \mathrm{abc}$ & $78.0 \mathrm{~b}$ & $2.50 \mathrm{ab}$ & $2.62 a b c$ \\
\hline $\mathrm{CNB}$ & $1.99 \mathrm{abcd}$ & $2.04 \mathrm{ab}$ & 10.10 & 10.75 & $2.33 \mathrm{ab}$ & $2.02 \mathrm{a}$ & $89.7 \mathrm{ab}$ & $92.6 \mathrm{ab}$ & $2.49 \mathrm{ab}$ & $2.62 \mathrm{abc}$ \\
\hline 2,5-DBB & $0.98 \mathrm{e}$ & $0.48 \mathrm{c}$ & 3.10 & 1.30 & $1.89 \mathrm{bc}$ & $1.27 \mathrm{c}$ & $60.5 \mathrm{~cd}$ & $43.5 \mathrm{~cd}$ & $1.98 \mathrm{~d}$ & $1.71 \mathrm{e}$ \\
\hline $2,5-\mathrm{DHB}$ & $2.58 \mathrm{ab}$ & $2.45 \mathrm{a}$ & 17.94 & 17.53 & $2.58 \mathrm{ab}$ & $2.15 \mathrm{a}$ & $96.7 \mathrm{ab}$ & $100.0 \mathrm{a}$ & $2.64 \mathrm{a}$ & $2.79 \mathrm{a}$ \\
\hline 3,6-DCP & $2.68 \mathrm{a}$ & $1.64 \mathrm{~b}$ & 18.08 & 6.83 & $2.88 \mathrm{a}$ & $1.66 \mathrm{ab}$ & $100.0 \mathrm{a}$ & $83.3 \mathrm{ab}$ & $2.67 \mathrm{a}$ & $2.52 \mathrm{abc}$ \\
\hline$P$ & 0.001 & $<0.001$ & $\ldots$ & $\ldots$ & 0.01 & 0.014 & 0.014 & $<0.001$ & 0.006 & $<0.001$ \\
\hline $\operatorname{LSD}(0.05)$ & 0.872 & 0.737 & $\ldots$ & $\ldots$ & 0.966 & 0.644 & 28.64 & 17.28 & 0.349 & 0.329 \\
\hline
\end{tabular}

y Tuber slices were then exposed to thaxtomin A (Desiree at $7 \mu \mathrm{M}$ and Russet Burbank at $14 \mu \mathrm{M}$ ) and mean necrosis ratings scored. Means followed by same letter within the same column are not significantly different at $P=0.05$ using Fisher's least significant difference (LSD) test; ns $=$ nonsignificant. Common scab disease measures (tuber surface cover, lesion depth score, and percent infected tuber) and thaxtomin A toxicity was determined following previous methods $(15,31,33)$.

${ }^{\mathrm{z}}$ Spray treatments included triple sequential sprays of $0.9 \mathrm{mM}$ 4-chloro-phenoxyacetic acid (4-CPA), 2,4-dichloro-phenoxyacetic acid (2,4-D), 2,4-D (amide form) (2,4-D [am]), 2,5-dichloro-phenoxyacetic acid (2,5-D), and 3,5-dichloro-phenoxyacetic acid (3,5-D); $1.6 \mathrm{mM}$ 5-chloro-2-nitrobenzoic acid (CNB), 2,5-dibromobenzoic acid (2,5-DBB), and 2,5-dihydroxybenzoic acid (2,5-DHB); $50 \mu \mathrm{M}$ 3,6-dichloropicolinic acid (3,6-DCP); or a control water treatment, with initial applications made 10 days after tuber initiation and subsequent applications at 10-day intervals. Total tuber numbers assessed per treatment were $\geq 25$ in pot trial 1 and $\geq 15$ in pot trials 2 and 3 . 
and 3,6-DCP) all have positive slopes with posterior probability 1 (Table 3 ) and correspond with chemicals that do not provide significant reduction in tuber disease, nor do they reduce toxin necrosis ratings. The second group (2,4-D (am), 3,5-D, 2,5-DBB, and $2,4-D)$ have lower slopes. The posterior probabilities that they have positive slopes range between 0.76 and 0.90 , indicating that they are all still likely to be increasing relationships (Table 3; Fig. 3). These correspond with chemicals that provide a significant reduction in tuber disease and an associated reduction in toxin necrosis ratings.

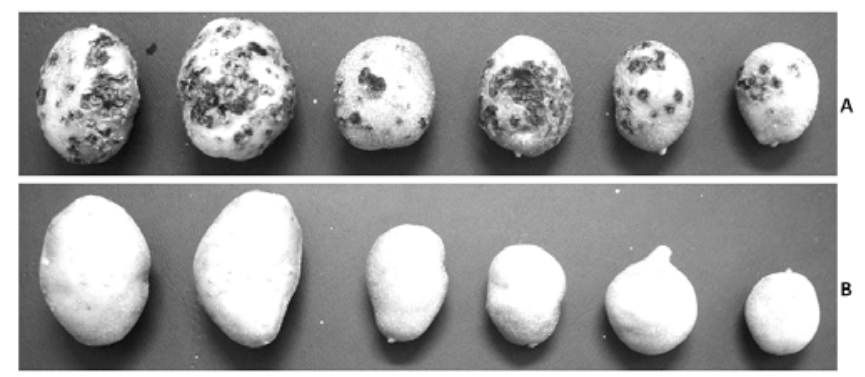

Fig. 1. Desiree tubers grown in soil amended with Streptomyces scabiei strain G\#32 (pot trial 3) and treated with 2,5-dibromobenzoic acid (2,5-DBB) foliar sprays. Spray treatments included A, no 2,5-DBB and B, 2,5-DBB three sequential sprays at $1.60 \mathrm{mM}$. Initial sprays were made 10 days after tuber initiation and subsequent sprays at 10 -day intervals.

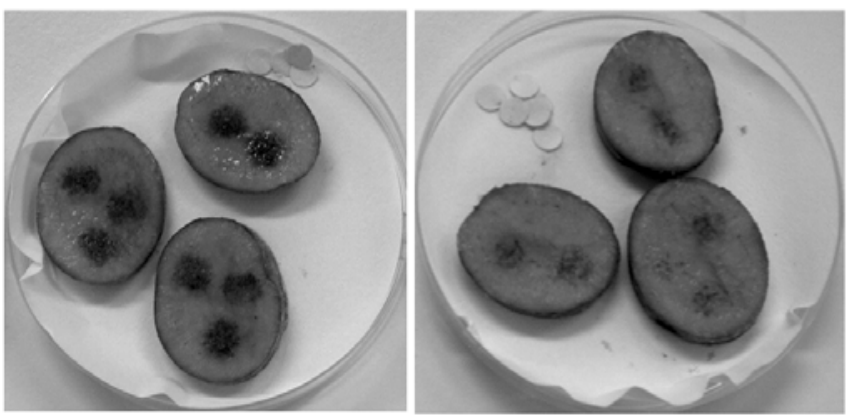

Fig. 2. Tuber slice assay for thaxtomin $A$ tolerance. Typical necrotic lesions on 'Desiree' tuber slices after 7 days of exposure to $14 \mu \mathrm{M}$ thaxtomin A (pot trial 3). Tubers on the left plate was from an unsprayed control plant (necrosis rating of 3.0) and tubers on the right plate was from a plant that received three spray treatments of $1.60 \mathrm{mM}$ 2,5-dibromobenzoic acid (2,5-DBB) (necrosis rating of 1.5).
For the five other analyses, similar trends were obtained showing that, as necrosis increases, so too does disease, (Fig. 4A-E). Each has a positive slope with posterior probabilities of at least 0.95. The magnitudes of the positive slopes for each graph are trial dependent (Table 3) and are a function of the relative levels of disease across each trial. The third trial, with much higher disease, where the highly pathogenic S. scabiei G\#32 was used (Table 2), was characterized by having slopes of 6.81 and 5.36 for Desiree and Russet Burbank, whereas the highest recorded slopes from either trials 1 or 2 (both with low disease) were 2.37 and 1.66 , respectively. Visual interpretation shows that certain treatments cluster into various parts of the linear regression. Treatments that reduced disease and toxin necrosis clustered toward the bottom left of the regression in all five analyses and included 2,5-DBB, 2,4-D, 2,4-D (am), and 3,5-D (Fig. 4A-E). The other six treatments (control, 4-CPA, 2,5-D, CNB, 2,5-DHB, and 3,6-DCP) that gave little or no significant reduction in either tuber disease or toxin sensitivity clustered from the middle toward the top right of the regressions in all five analyses. This clustering results from the varying efficaciousness of each chemical but there remains an overall trend in each trial between disease severity and necrosis measure, thus providing a linkage between the two measures. Using dashed lines in Figure 4, we show the simple linear regressions that would be obtained if no adjustment had been made for measurement error. In each case, the slopes were smaller. This was the result of the measurements with smaller precision being given equal weight to more precise measurements.

\section{Discussion}

The suppression of common scab symptom development by various compounds has been previously demonstrated in a series of glasshouse and field trials (20-23,30). Our three replicated pot trials generally support previous findings and confirm a range of compounds as able to significantly suppress disease. In this study, the two dichlorophenoxyacetic acids (2,4-D and 3,5-D) consistently negated disease development by an average of 73.7 and $61.2 \%$, respectively, and we also confirmed the disease negating impact of 2,4-D (am). These compounds, however, when used at concentrations as in prior studies (21-23) and the study reported here, have phytotoxic effects, with yield reduction and tuber distortion (elongated shape), which have previously precluded the use of these chemicals in commercial operations. Whereas the work presented in this study used concentrations of the dichlorophenoxyacetic acids that were expected to be phytotoxic, current work in our laboratory suggests that 2,4-D can be applied at significantly lower concentrations, reducing phytotoxic effects but still provid-

Table 3. Summary of the relationship between common scab disease (tuber surface cover score) and thaxtomin-A-induced necrosis for each trial and cultivar $^{\mathrm{y}}$

\begin{tabular}{|c|c|c|c|c|}
\hline Trial, cultivar & Treatment $^{\mathrm{z}}$ & Intercept $(\alpha)$ & Slope $(\beta)$ & $P($ slope $>0)$ \\
\hline $\begin{array}{l}\text { 1, Desiree } \\
\text { 2, Desiree } \\
\text { 3, Desiree } \\
\text { 2, Russet Burbank } \\
\text { 3, Russet Burbank }\end{array}$ & $\begin{array}{l}\text { Control } \\
2,4-\mathrm{D} \\
2,4-\mathrm{D}(\mathrm{am}) \\
2,5-\mathrm{D} \\
3,5-\mathrm{D} \\
4-\mathrm{CPA} \\
\text { CNB } \\
2,5-\mathrm{DBB} \\
2,5-\mathrm{DHB} \\
3,6-\mathrm{DCP} \\
- \\
- \\
- \\
- \\
-\end{array}$ & $\begin{array}{c}-3.99(-6.93,-1.84) \\
-0.53(-2.51,0.66) \\
-1.33(-4.00,1.15) \\
-3.29(-6.48,-1.34) \\
-0.92(-3.05,1.51) \\
-2.83(-5.37,-0.95) \\
-3.14(-5.95,-1.13) \\
-0.83(-2.70,0.73) \\
-3.35(-6.21,-1.25) \\
-2.74(-5.28,-0.87) \\
-5.94(-12.93,-2.67) \\
-3.34(-10.13,-0.84) \\
-14.69(-50.23,-2.89) \\
-1.97(-5.96,-0.08) \\
-12.05(-35.87,-2.80)\end{array}$ & $\begin{array}{l}1.66(0.81,2.83) \\
0.23(-0.26,1.07) \\
0.57(-0.45,1.67) \\
1.39(0.61,2.68) \\
0.42(-0.55,1.30) \\
1.20(0.46,2.21) \\
1.32(0.50,2.42) \\
0.36(-0.29,1.13) \\
1.42(0.54,2.50) \\
1.17(0.40,2.16) \\
2.37(1.10,4.92) \\
1.39(0.40,3.98) \\
6.81(1.96,21.46) \\
0.89(0.12,2.48) \\
5.36(1.66,14.82)\end{array}$ & $\begin{array}{l}1.00 \\
0.76 \\
0.93 \\
1.00 \\
0.87 \\
1.00 \\
1.00 \\
0.90 \\
1.00 \\
1.00 \\
0.95 \\
0.99 \\
0.99 \\
0.99 \\
0.99\end{array}$ \\
\hline
\end{tabular}

${ }^{y}$ Shown are the posterior mean intercept and slope (95\% credible interval) and the posterior probability that the slope is positive. For trial 1 (Russet Burbank) separate regressions are provided for each chemical treatment, whereas only a single regression was required for all other trials.

${ }^{z}$ Abbreviations: 4-chloro-phenoxyacetic acid (4-CPA), 2,4-dichloro-phenoxyacetic acid (2,4-D), 2,4-D (amide form) (2,4-D [am]), 2,5-dichlorophenoxyacetic acid (2,5-D), 3,5-dichloro-phenoxyacetic acid (3,5-D), 5-chloro-2-nitrobenzoic acid (CNB), 2,5-dibromobenzoic acid (2,5-DBB), 2,5dihydroxybenzoic acid (2,5-DHB), and 3,6-dichloropicolinic acid (3,6-DCP). 
ing substantial disease suppression, and may be a control option in the future, with further work on rates and timing of application ongoing.

As an alternative to the dichlorophenoxyacetic acids, other less phytotoxic chemicals have been identified that suppress common scab without yield or the shape of the tuber being significantly affected (20). Such chemicals include the di-substituted benzoic and picolinic acids tested in this work. Confirming previous work (30), we showed that CNB did not significantly and consistently

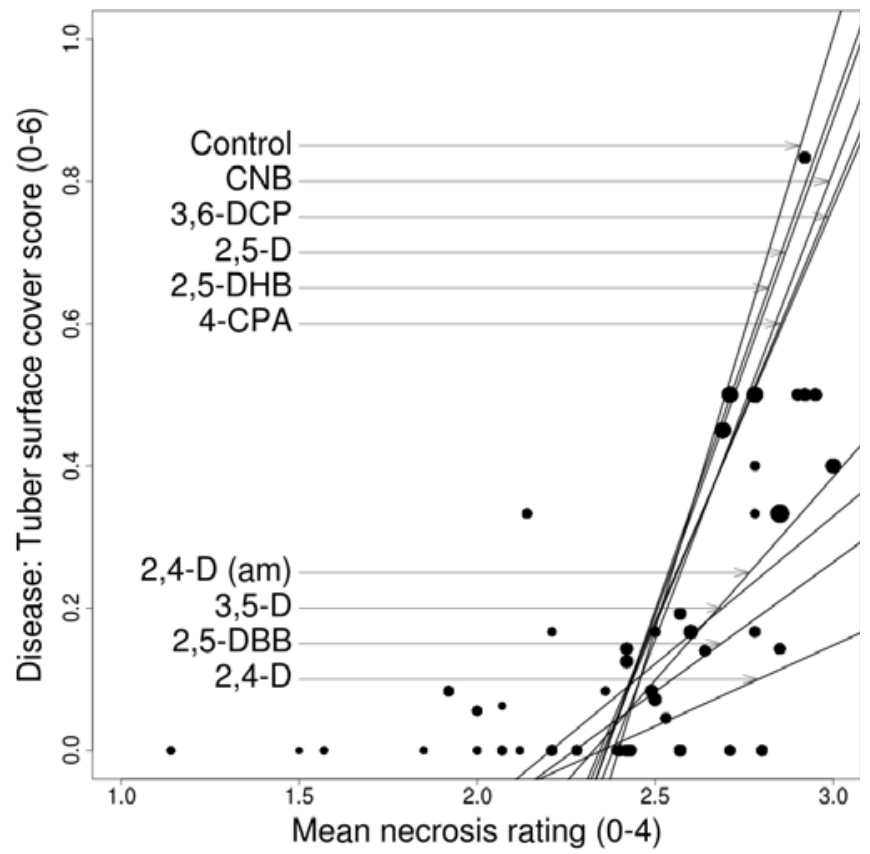

Fig. 3. Relationship between common scab disease (tuber surface cover score) and thaxtomin-A-induced necrosis for 'Russet Burbank' (trial 1). Lines represent the mean posterior predicted fits for each chemical treatment. Observed data are shown as dots, with the size of each proportional to the precision of the necrosis data. suppress common scab. Whereas this contradicts the work of McIntosh and co-workers (20), who found substantial disease suppression with this compound in one trial (73\% scab reduction), our results have included four separate pot trials, and supporting thaxtomin A toxicity data (discussed below) suggest that CNB is not a compound which will suppress this disease. Likewise we found that the disease suppression obtained by McIntosh for 3,6DCP in one trial ( $73 \%$ scab reduction) was not obtained in our three pot trials and is supported by thaxtomin A toxicity data (discussed below). In contrast, results obtained with two other dibenzoic acids strongly support the work of McIntosh and coworkers (20). This includes 2,5-DHB, which did not suppress scab, and 2,5-DBB, which produced significant diseasesuppressive effects.

Overall, our modeling of disease suppression and thaxtomin A sensitivity suggested that, for all 10 treatments, there was a consistent relationship between these two variables on both potato cultivars. This model may enable the development of a screening technique in which future collection of disease-based data could be minimized. These findings are supported by recent potato breeding work where thaxtomin A was successfully used as a selective screening agent to identify common scab sensitive progeny (12).

The modeling presented in this article conclusively links disease suppression and toxin sensitivity for the given cultivar being tested and provides an added tool for future studies where there is a need to assess chemical efficacy in controlling common scab disease. From a practical perspective, disease-based trials are highly useful in determining applicability of chemical controls but many common scab disease trials are often compromised, with low or no disease outcomes $(12,29)$; therefore, it is difficult to predict effectiveness of treatments. Evaluating thaxtomin sensitivities using the tuber slice bioassay is an easy and highly repeatable assay (31) that serves to provide an accurate measure of potential to suppress disease. It must be stated that there are other chemical products that act via different modes of action to induce resistance or control this disease that don't specifically target thaxtomin A. Such chemicals include various fungicides that directly target the pathogen $(19,21)$ and, in such cases, evaluating thaxtomin sensitivity will not provide a measure of the potential to suppress disease.

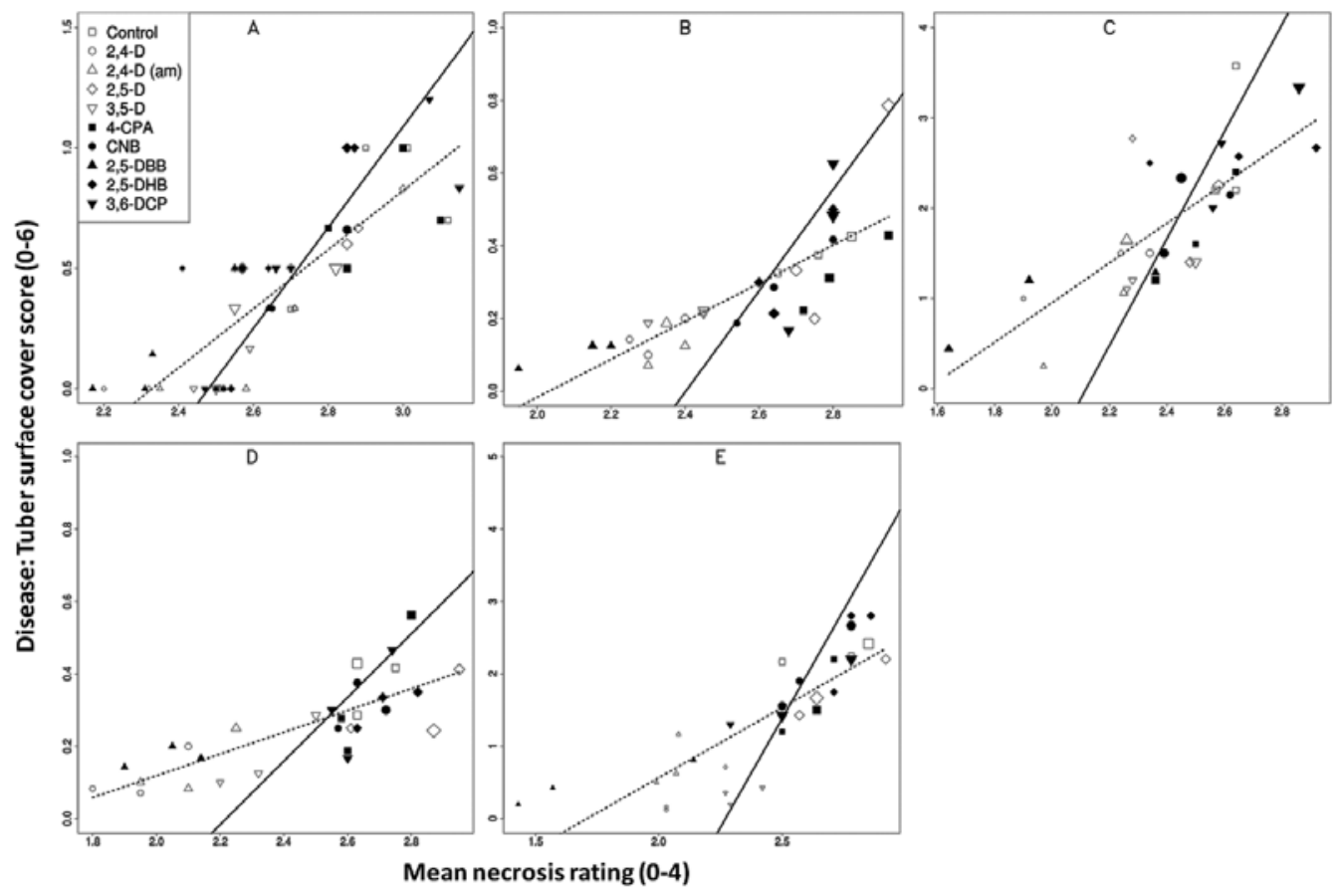

Fig. 4. Relationship between common scab disease (tuber surface cover score) and thaxtomin-A-induced necrosis for $\mathbf{A}$, trial 1, Desiree; $\mathbf{B}$, trial 2, Desiree; C, trial 3 , Desiree; D, trial 2, Russet Burbank; and E, trial 3, Russet Burbank. The solid line represents the mean posterior predicted fit. Also shown as a dashed line is the fitted least squares simple linear regression that does not take into account the errors in measurement. Observed data are shown as symbols, with the size of each proportional to the precision of the necrosis data. 
Despite measurement errors, our modeling approach allowed us to extract the trends between disease (tuber surface cover score) and toxin sensitivity. A Bayesian framework for measurement error model can be more flexible than conventional approaches and more easily allow for the integration of various sources of measurement error (26). The modeling approach used illustrates that the use of regression may be considerably misleading unless the existence of error in explanatory variables is taken into account. In regression models with a single predictor variable that is measured with independent random error, the slope will be underestimated, an effect termed regression dilution (7). This would be equivalent to reducing the significance of the regression slope and, therefore, both statistically and biologically significant effects would be missed. Although we estimated the error in the explanatory variables from other data, we could have estimated it within the model if that had been necessary. The Bayesian context also permits the construction of more complex models with easily available software.

The above studies provide evidence that extent of disease suppression induced by the application of certain chemicals is intimately linked to the inherent susceptibility of the tuber tissue (containing that chemical; 30) to thaxtomin A. Indeed, the efficaciousness of the chemical treatment may potentially be estimated using appropriate Bayesian models with future collection of disease-based data minimized. This work provides increased knowledge of the disease and potential rapid assays for identifying suitable chemical controls that work through foliar application and systemic movement into the tuber tissue. Whereas thaxtomin A resistance is only one factor that may determine common scab resistance (31), in this case of chemical-induced resistance it appears to be a central component to better understanding the unique mechanisms by which these treatments control this disease.

\section{Acknowledgments}

The research presented is a part of the Australian Potato Research Program (Phase 2). It is funded by Horticulture Australia Limited using the processing potato industry levy and voluntary contributions from the A\&L Canada Laboratories and the New Zealand Institute of Plant and Food, and matched funds from the Federal Government.

\section{Literature Cited}

1. Acuna, I. A., Strobel, G. A., Jacobsen, B., and Corsini, D. L. 2001. Glucosylation as a mechanism of resistance to thaxtomin A in potatoes. Plant Sci. 161:77-88.

2. Babcock, M., Eckwall, E. C., and Schottel, J. L. 1993. Production and regulation of potato-scab-inducing phytotoxins by Streptomyces scabies. J. Gen. Microbiol. 139:1579-1586.

3. Brooks, S. P. 2003. Bayesian computation: a statistical revolution. Philos. Trans. R. Soc. Lond. A 361:2681-2697.

4. Brooks, S. P., and Roberts, G. O. 1998. Convergence assessment techniques for Markov chain Monte Carlo. Stat. Comput. 8:319-335.

5. Carroll, R. J., Roeder, K., and Wasserman, L. 1999. Flexible measurement error models. Biometrics 55:44-54.

6. Dellaportas, P., and Stephens, D. A. 1995. Bayesian analysis of errors-invariables regression models. Biometrics 51:1085-1095.

7. Frost, C., and Thompson, S. 2000. Correcting for regression dilution bias: comparison of methods for a single predictor variable. J. R. Stat. Soc. Ser. A 163:173-190.

8. Fuller, W. A. 1987. Measurement Error Models. Wiley, New York.

9. Gelman, A., Carlin, J. B., Stern, H. S., and Rubin, D. B. 2000. Bayesian Data Analysis. Chapman \& Hall/CRC, London.

10. Gilks, W. R., Richardson, S., and Spiegelhalter, D. J. 1998. Markov Chain Monte Carlo in Practice. Chapman \& Hall/CRC, London.

11. Goyer, C., Vachon, J., and Beaulieu, C. 1998. Pathogenicity of Streptomyces scabies mutants altered in thaxtomin A production. Phytopathology 88:442445.

12. Hiltunen, L. H., Alanen, M., Laakso, I., Kangas, A., Virtanen, E., and Valkonen, J. P. T. 2011. Elimination of common scab sensitive progeny from a potato breeding population using thaxtomin A as a selective agent. Plant Pathol. 60:426-435.

13. Hiltunen, L. H., Laakso, I., Chobot, V., Hakala, K. S., Weckman, A., and Valkonen, J. P. T. 2006. Influence of thaxtomins in different combinations and concentrations on growth of micropropagated potato shoot cultures. J. Agric. Food Chem. 54:3372-3379.

14. Kers, J. A., Cameron, K. D., Joshi, M. V., Bukhalid, R. A., Morello, J. E. Wach, M. J., Gibson, D. M., and Loria, R. 2005. A large, mobile pathogenicity island confers plant pathogenicity on Streptomyces species. Mol. Microbiol. 55:1025-1033.

15. Khatri, B. B., Tegg, R. S., Brown, P. H., and Wilson, C. R. 2011. Temporal association of potato tuber development with susceptibility to common scab and Streptomyces scabiei-induced responses in the potato periderm. Plant Pathol. 60:776-786.

16. King, R. R., Lawrence, C. H., and Clark, M. C. 1991. Correlation of phytotoxin production with pathogenicity of Streptomyces scabies isolates from scab infected potato tubers. Am. Potato J. 68:675-680.

17. Lapwood, D. H., and Adams, M. J. 1973. The effect of a few days of rain on the distribution of common scab (Streptomyces scabies) on young potato tubers. Ann. Appl. Biol. 73:277-283.

18. Lapwood, D. H., and Adams, M. J. 1975. Mechanisms of control of common scab by irrigation. Pages 123-129 in: Biology and Control of Soil Borne Pathogens. G. W. Bruehl, ed. American Phytopathological Society, St. Paul, MN.

19. Loria, R., Kers, J., and Joshi, M. 2006. Evolution of plant pathogenicity in Streptomyces. Annu. Rev. Phytopathol. 44:469-487.

20. McIntosh, A. H., Bateman, G. L., and Chamberlain, K. 1988. Substituted benzoic and picolinic acids as foliar sprays against potato common scab. Ann. Appl. Biol. 112:397-401.

21. McIntosh, A. H., Bateman, G. L., Chamberlain, K., Dawson, G. W., and Burrell, M. M. 1981. Decreased severity of potato common scab after foliar sprays of 3,5-dichlorophenoxyacetic acid, a possible antipathogenic agent. Ann. Appl. Biol. 99:275-281.

22. McIntosh, A. H., Burrell, M. M., and Hawkins, J. H. 1982. Field trials of foliar sprays of 3,5-dichlorophenoxyacetic acid (3,5-D) against common scab on potatoes. Potato Res. 25:347-350.

23. McIntosh, A. H., Chamberlain, K., and Dawson, G. W. 1985. Foliar sprays against potato common scab: compounds related to 3,5-dichlorophenoxyacetic acid. Crop Prot. 4:473-480.

24. Plummer, M. 2006. JAGS, Just Another Gibbs Sampler Software. SourceForge open source software. http://www-fis.iarc.fr/ martyn/software/jags/.

25. Que Hee, S. S., and Sutherlan, R. G. 1981. The Phenoxyalkanoic Herbicides, Vol. I. Chemistry, Analysis and Environmental Pollution. CRC Press, Boca Raton, FL.

26. Richardson, S. 1998. Measurement error. In: Markov Chain Monte Carlo in Practice. W. R. Gilks, S. Richardson, and D. J. Spiegelhalter, eds. Chapman \& Hall/CRC, London.

27. Shirling, E. B., and Gottlieb, D. 1966. Methods for characterisation of Streptomyces species. Int. J. Syst. Bacteriol. 16:313-340.

28. Stefanski, L. A., and Carroll, R. 1985. Covariate measurement error in logistic regression. Ann. Stat. 14:1335-1351.

29. Tarn, T. R., Murphy, A. M., and King, R. R. 2004. Potato scab in Canada: breeding approaches for the control of potato scab. Pages 137-148 in: Proc. Int. Potato Scab Sympos. (IPSS 2004), Sapporo, Japan. S. Naito, N. Kondo, S. Akino, A. Ogoshi, and F. Tanaka, eds. Hokkaido University, Sapporo, Japan.

30. Tegg, R. S., Gill, W. M., Thompson, H. K., Davies, N. W., Ross, J. J., and Wilson, C. R. 2008. Auxin-induced resistance to common scab disease of potato linked to inhibition of thaxtomin A toxicity. Plant Dis. 92:1321-1328.

31. Tegg, R. S., and Wilson, C. R. 2010. Relationship of resistance to common scab disease and tolerance to thaxtomin A toxicity within potato cultivars. Eur. J. Plant Pathol. 128:143-148.

32. Waterer, D. 2010. Influence of growth regulators on skin colour and scab diseases of red-skinned potatoes. Can. J. Plant Sci. 90:745-753.

33. Wilson, C. R. 2001. Variability within clones of potato cv. Russet Burbank to infection and severity of common scab disease of potato. J. Phytopathol. 149:625-628

34. Wilson, C. R., Luckman, G. A., Tegg, R. S., Yuan, Z. Q., Wilson, A. J., Eyles, A., and Conner, A. J. 2009. Enhanced resistance to common scab of potato through somatic cell selection in cv. Iwa with the phytotoxin thaxtomin A. Plant Pathol. 58:137-144.

35. Wilson, C. R., Tegg, R. S., Wilson, A. J., Luckman, G. A., Eyles, A., Yuan, Z. Q., Hingston, L. H., and Conner, A. J. 2010. Stable and extreme resistance to common scab of potato obtained through somatic cell selection. Phytopathology 100:460-467. 